\title{
TERRITORIO Y ÁREAS PROTEGIDAS EN ESPAÑA Y PORTUGAL: DOS MODELOS DE INTERVENCIÓN EN UNA GEOGRAFÍA COMPARTIDA ${ }^{1}$
}

\author{
Alfonso Mulero Mendigorri \\ Departamento de Geografía y Ciencias del Territorio. Universidad de Córdoba \\ alfonso.mulero@uco.es
}

\section{RESUMEN}

En las últimas tres décadas la Península Ibérica ha conocido una expansión sin precedentes de sus espacios naturales protegidos, con unas consecuencias ecológicas, territoriales y socioeconómicas extraordinarias. En el presente trabajo se analiza la forma en que España y Portugal han desarrollado tal intervención protectora, atendiendo a los objetivos y criterios seguidos en la selección, planificación y gestión de sus respectivas áreas protegidas. A juicio del autor, el estudio del caso ibérico permite comprender los procesos de configuración y ordenación de las redes de áreas protegidas en estados limítrofes de la Unión Europea, así como los contrastes existentes entre ellos y la necesidad de lograr una mayor armonización interterritorial.

Palabras clave: áreas protegidas; Península Ibérica; parques naturales; ordenación del territorio; protección de la naturaleza.

Fecha de recepción: septiembre 2015.

Fecha de aceptación: diciembre 2016.

1 Este trabajo ha sido elaborado en el marco de la estancia de investigación realizada por el autor en la Universidad de Lisboa, financiada por el Programa de Fortalecimiento de las Capacidades de I+D+i de la Universidad de Córdoba (2014). 


\section{ABSTRACT}

Over the last three decades the Iberian Peninsula has experienced an unprecedented expansion of its protected natural areas, with extraordinary ecological, territorial and socioeconomic consequences. This essay analyses the way in which Spain and Portugal have developed such a protective intervention policy, according to the objectives and criteria used in the selection, planning and management of their protected areas. In our view, the Iberian case study alow us to understand processes of configuration and management of networks of protected areas in bordering states of the European Union, with the aim of pointing the existing contrasts and the need for further harmonisation between territories.

Keywords: protected areas; Iberian Peninsula; natural parks; land-use planning; protection of nature.

\section{INTRODUCCIÓN: OBJETIVOS E HIPOTESIS DE TRABAJO}

España y Portugal, a pesar de su dispar trayectoria histórica en materia de áreas protegidas $^{2}$, tienen en común haber carecido de una red significativa de las mismas hasta tiempos recientes. En efecto, todavía en 1980 (Tabla 1) los escasos ámbitos declarados no tenían consistencia territorial ni socioeconómica, ni tampoco eran suficientemente representativos de la extraordinaria biodiversidad que registra la Península Ibérica. Se trata de una constatación alarmante si se considera la importancia biogeográfica de esta península en su contexto territorial: equivale al 6\% de Europa Occidental, pero alberga alrededor del 50\% de las especies europeas de plantas y vertebrados terrestres, así como el $31 \%$ de endemismos censados de ambos grupos (Araujo, Lobo y Moreno, 2007).

Por fortuna, en los últimos decenios el panorama ha cambiado de forma radical. La irrupción en la década de los setenta de un nuevo paradigma ambiental ha derivado en una revalorización sustancial de las áreas protegidas, que en el caso de España y Portugal se inició, ya por aquéllas fechas, con un decidido impulso normativo ${ }^{3}$ que puede interpretarse como el preámbulo de la etapa expansiva en que nos encontramos inmersos. Hasta el momento actual las cifras alcanzadas son contundentes: el $22 \%$ del territorio portugués y el $28 \%$ del español se encuentran sujetos a protección bajo alguna figura regional, estatal o internacional, y sus consecuencias ecológicas, territoriales y socioeconómicas están siendo extraordinarias. Pero, como es lógico, una expansión de tal magnitud ha de interpretarse considerando vectores complementarios que van más allá del afán de preservación de la biodiversidad, tales como las crisis y mutaciones recientes acaecidas en los medios rurales europeos $-\mathrm{y}$ su

2 En España se considera a la Ley de Creación de Parques Nacionales de 1916 el punto de partida de la política específica de espacios naturales protegidos. En Portugal tiene el mismo significado la Ley $\mathrm{n}^{\circ}$ 9/1970, de 19 de junio, sobre Parques Nacionales y otros tipos de reservas. Para un acercamiento a la evolución de la política protectora, pueden consultarse, entre otros, Casado (1997) y Mulero (2002) para el caso español, y Pinto (2008), Landovsky y Mendes (2012), y Morais (2012) para el portugués.

3 Ley sobre Parques Nacionales y otros tipos de Reservas de 1970 (Portugal) y Ley de Espacios Naturales Protegidos de 1975 (España). 
reorientación hacia nuevos modelos de desarrollo sostenible vinculados a áreas protegidas (Jollivet, 1997; Figueredo, 2008 a y b)- o, también, el crecimiento sostenido de la demanda de espacios rurales de ocio y, específicamente, de parques y reservas naturales por parte de las poblaciones urbanas (Mulero, 1995).

Tabla 1

EVOLUCIÓN DE LOS ESPACIOS NATURALES PROTEGIDOS CONVENCIONALES EN LA PENÍNSULA IBÉRICA (1980-2013/15) (1)

\begin{tabular}{|l|c|c|c|c|c|c|}
\hline & $\begin{array}{c}\text { Áreas } \\
\text { Protegidas } \\
\text { (1980) }\end{array}$ & $\begin{array}{c}\text { Superficie } \\
\text { (ha) } \\
(\mathbf{1 9 8 0})\end{array}$ & $\begin{array}{c}\text { \% extensión } \\
\text { peninsular } \\
\text { del país }\end{array}$ & $\begin{array}{c}\text { Áreas } \\
\text { Protegidas } \\
(\mathbf{2 0 1 3 / 1 5})\end{array}$ & $\begin{array}{c}\text { Superficie } \\
\text { (ha) } \\
(\mathbf{2 0 1 3 / 2 0 1 5})\end{array}$ & $\begin{array}{c}\text { \% extensión } \\
\text { peninsular } \\
\text { del país }\end{array}$ \\
\hline $\begin{array}{l}\text { España } \\
\text { peninsular }\end{array}$ & 23 & 184.270 & 0.4 & 1.662 & 6.577 .712 & 13,4 \\
\hline $\begin{array}{l}\text { Portugal } \\
\text { peninsular }\end{array}$ & 10 & 329.168 & 3.4 & 46 & 792.220 & 8.6 \\
\hline
\end{tabular}

Los datos van referidos a las redes convencionales de espacios protegidos en el territorio peninsular. No se incluyen por tanto los correspondientes a los archipiélagos de Madeira, Azores, Canarias y Baleares. Tampoco se consideran los espacios protegidos de la Red Natura ni de otras iniciativas internacionales (para España la información es de 2013, último año con datos fiables publicados).

Fuente: Elaboración propia a partir de Europarc España; Ministerio de Agricultura y Medio Ambiente (España); Instituto da Conservaçao da Natureza e das Florestas (Portugal).

En tal contexto general, el análisis del caso ibérico - una vez cerrado en lo esencial el reciente ciclo protector expansivo- permite comprender el proceso de configuración y ordenación de las nuevas redes de áreas protegidas en dos estados limítrofes de la Unión Europea que gozan de notable continuidad biogeográfica. A nuestro juicio, se trata de un asunto de notable interés por tres razones fundamentales: (1) porque la riqueza que en términos de biodiversidad caracteriza a esta península podría verse comprometida de aplicarse intervenciones protectoras contradictorias a ambos lados de la frontera; (2) porque en la actualidad el fortalecimiento de la conectividad entre territorios de singular valor ecológico y la consolidación de redes homogéneas de áreas protegidas son objetivos esenciales de las políticas internacionales de conservación del medio natural, y más aún cuando se trata de ámbitos fronterizos como éstos; y (3) porque estas mismas directrices internacionales reconocen la necesidad de lograr una mayor implicación de las comunidades locales en el manejo de las áreas protegidas, cuestión ésta muy debatida tanto en España como en Portugal.

En lo relacionado con la estructura expositiva de este trabajo, hemos considerado oportuna -ante la inexistencia de antecedentes sobre la cuestión- la inclusión de un apartado inicial de carácter contextualizador e introductorio, en el que presentamos las directrices que Portugal y España han incorporado en los últimos años a sus respectivos ordenamientos jurídicos, a fin de encauzar la reciente expansión protectora. A continuación, en un segundo apartado, expondremos de forma sintética los resultados y conclusiones extraídas 
del análisis documental, del trabajo de campo y de la evaluación de la gestión de las áreas protegidas que hemos llevado a cabo. Partimos de la hipótesis de que, tras una aparente convergencia programática, en la práctica cada país está aplicando una estrategia protectora diferente, dando paso a dos modelos dispares de ordenación y gestión de tales áreas en el territorio peninsular.

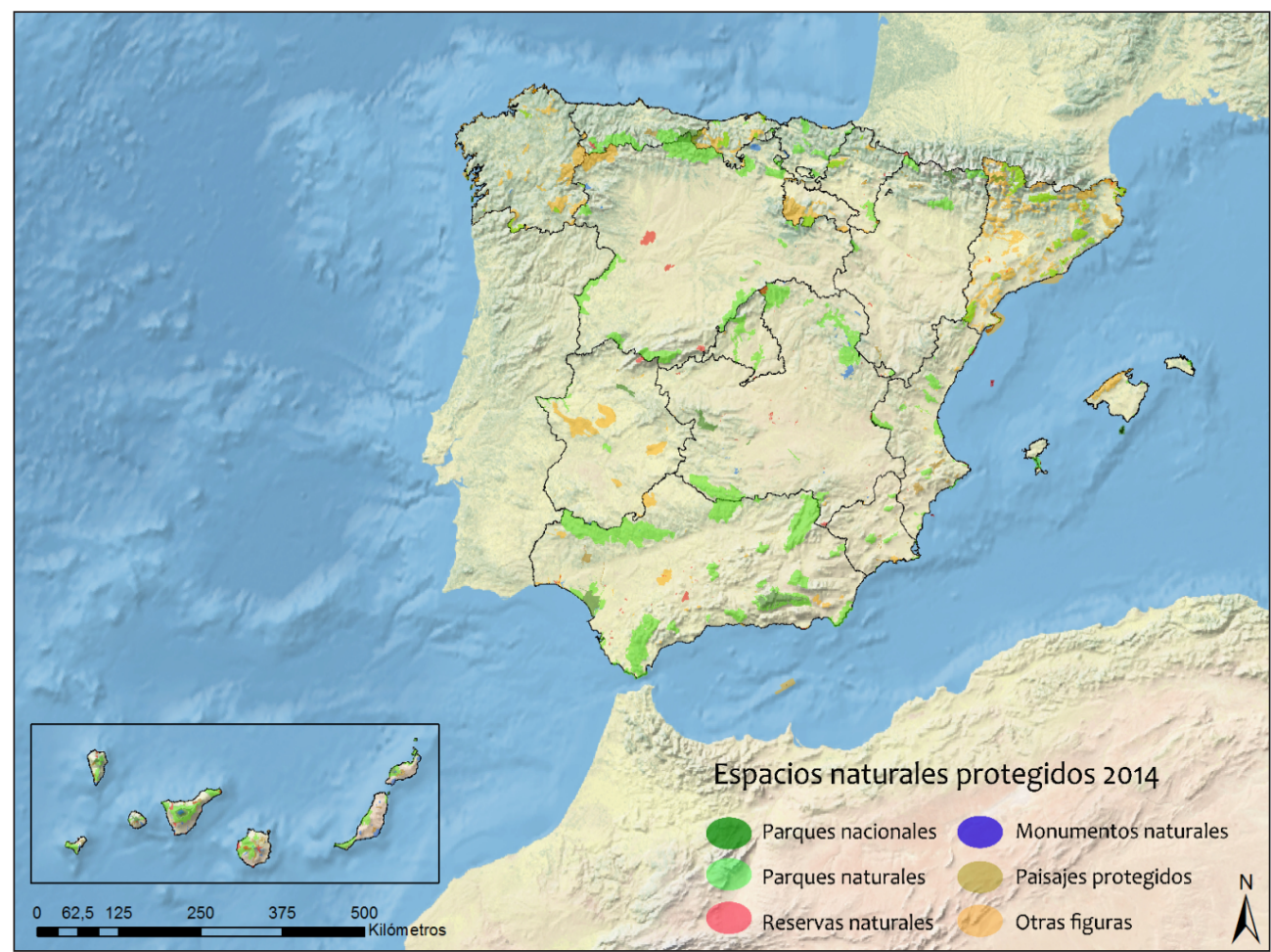

Fuente: Europarc, 2014 y elaboración propia.

Es preciso aclarar, a efectos metodológicos, que este artículo se ocupa de las iniciativas propias de ambos Estados -sin entrar a considerar los compromisos y convenios internacionales a que cada uno se encuentra vinculado- y, como es obvio, sólo en lo referido al ámbito peninsular, por razón de la continuidad territorial y de esa "geografía compartida" que es el argumento principal de nuestra investigación; ni que decir tiene que la incorporación de los diferentes archipiélagos alteraría esta perspectiva, sobre todo en relación con Portugal, donde Azores y Madeira - por su condición de regiones autónomas- han desarrollado sistemas de protección que muy poco tienen que ver con lo acaecido en el resto del país. 
Figura 2

RED NACIONAL DE ÁREAS PROTEGIDAS

DE PORTUGAL CONTINENTAL (2015)



Fuente: Instituto da Conservaçao da Natureza e das Florestas (2015), y elaboración propia. 


\section{LOS NUEVOS POSTULADOS EN MATERIA PROTECTORA Y SU TRASLACIÓN AL MARCO POLÍTICO-NORMATIVO PENINSULAR}

Los renovados sistemas de protección que hoy podemos contemplar en los estados peninsulares son el resultado de un importante cambio de mentalidad acompañado de sustanciales transformaciones de orden jurídico-normativo, socioeconómico y territorial. Es bien sabido que el germen teórico de tan importantes cambios se encuentra en el nuevo paradigma en torno al desarrollo sostenible y la preservación de la biodiversidad que se ha ido asentando en la escena mundial desde la década de los setenta, uno de cuyos efectos principales ha sido la revisión de las políticas de conservación de la naturaleza y, específicamente, de los sistemas tradicionales de áreas protegidas, considerados ya insuficientes para afrontar con eficacia los retos que la actual situación demanda a escala mundial. Pues bien, del análisis de las políticas protectoras recientes llevadas a cabo en España y Portugal se desprende que ambos Estados han procedido a esta renovación de forma bastante paralela y coincidente, tanto en lo referido a la actualización jurídica llevada a cabo desde finales de los años ochenta, como en la transformación de los organismos competentes de tales políticas, o, finalmente, en el establecimiento de unos criterios bastante similares, según se explica a continuación.

\section{II.1. Una concepción más holística del patrimonio natural y de su gestión territorial}

El primero y esencial de los nuevos criterios compartidos radica en que el patrimonio natural territorial -aquél distinguido mediante la designación de áreas protegidas u otros tipos de categorías-, debe ser clasificado y gestionado desde criterios holísticos, al objeto de mejorar su funcionalidad. Con tal fin se promulgó la ley española del Patrimonio Natural y de la Biodiversidad (en adelante LPNB) de $2007^{4}$, que derogó a la de Conservación de Espacios Naturales y de la Flora y Fauna Silvestres (1989) se anuncia el citado cambio de paradigma y la concepción mucho más integradora a que se aspira: el centro de atención se desplaza desde el "espacio natural protegido" al conjunto del "patrimonio natural", y desde la preservación de la "flora y fauna silvestres" a la totalidad de la "biodiversidad". Portugal, por su parte, ha recorrido un camino bastante paralelo con la promulgación de un nuevo Decreto-Ley sobre Conservación de la Naturaleza y la Biodiversidad (en adelante DLCNB) en $2008^{6}$, que supera ampliamente al texto de 1993 regulador de la Red Nacional de Áreas Protegidas ${ }^{7}$. Algunos de los nuevos instrumentos introducidos con tal perspectiva holística son:

4 Ley 42/2007, de 13 de diciembre, del Patrimonio Natural y de la Biodiversidad. BOE no 299 , de 14 de diciembre de 2007. Modificada por Ley 33/2015, de 21 de septiembre.

5 Ley 4/1989, de 27 de marzo, de Conservación de Espacios Naturales y de la Flora y Fauna Silvestres. BOE $\mathrm{n}^{\mathrm{o}} 77$, de 28 de marzo de 1989.

6 Decreto-Lei $\mathrm{n}^{\circ}$ 142/2008, de 24 de Julho, de Conservaçâo da Natureza e da Biodiversidade. Diário da República $1^{\text {a }}$ Série, $\mathrm{n}^{\mathrm{o}} 142$ (24 Julho de 2008).

7 Decreto-Lei, no 19/1993, de 23 de Janeiro. Diário da República $1^{\text {a }}$ Série, nº 19 (23 de Janeiro de 1993). 
a) La voluntad de preservación del patrimonio natural y de la biodiversidad en su conjunto (y no sólo de espacios y/o especies concretas) se sitúa como eje central de las nuevas políticas peninsulares, comenzando por el renovado interés por inventariarlo y lograr un mejor conocimiento del mismo. Con tal fin, la vigente ley española ha estipulado la creación del Inventario del Patrimonio Natural y la Biodiversidad, en tanto que el decreto-ley portugués ha procedido de igual forma con el Sistema de Información sobre el Patrimonio Natural y el Catastro Nacional de Valores Naturales Clasificados.

b) Otro claro ejemplo se encuentra en el ejercicio de sistematización y clasificación de las numerosas figuras de protección que han venido proliferando desde la década de los setenta al amparo de acuerdos y convenios internacionales diversos (Reservas de la Biosfera, Humedales Ramsar, Lugares Patrimonio de la Humanidad, Red Natura, Geoparques, Zonas de Especial Importancia para el Mediterráneo, etc.), con la intención de lograr cierta armonización con las categorías propias de cada país. Al respecto, en la LPNB los capítulos segundo a cuarto están dedicados respectivamente a la definición y regulación de los Espacios Naturales Protegidos, de los Espacios Protegidos Red Natura 2000, y de las Áreas Protegidas por Instrumentos Internacionales, mientras que el quinto establece la creación del Inventario Español que agrupará a todos ellos. Y similar intención y estructura manifiesta la legislación lusa, al definir un Sistema Nacional de Áreas Clasificadas, integrado por los siguientes componentes: Red Nacional de Áreas Clasificadas, Red Natura 2000 y Áreas abarcadas por designaciones de conservación de carácter supranacional (DLCNB, cap. II).

c) El énfasis puesto en los conceptos de red y corredor ecológico también apunta hacia el fortalecimiento de la matriz territorial de la protección. Ambos se han convertido en piezas centrales de las renovadas políticas de conservación en todo el planeta, desde el convencimiento de que su eficacia pasa por lograr la máxima conectividad ecológica entre los hábitats de mayor relevancia. Nótese que instancias y organismos internacionales comprometidos desde los años setenta con la protección del medio natural insisten en los últimos años en la potenciación del modelo de red en la organización de las áreas protegidas auspiciadas por ellos (en la actualidad se habla de Red de Reservas de la Biosfera, Red de Humedales Ramsar, etc. ); pero también las nuevas iniciativas protectoras vienen ya regidas por tal modelo, con ejemplos antológicos en la Red Natura 2000 de la Unión Europea -a escala supraestatal- o la Red de Espacios Naturales Protegidos de Andalucía (RENPA) -a escala regional-, por citar dos casos significativos del interés puesto en la necesidad de mejorar la trabazón territorial como estrategia para la preservación de la biodiversidad.

Por otro lado, la promoción de los corredores ecológicos también se explica por tal necesidad, aunque en este caso con la pretensión de conectar el conjunto de piezas territoriales que integran el patrimonio natural, formen parte o no de las redes convencionales de áreas protegidas (Mulero, 2015). Al respecto, en el territorio ibérico el decreto-ley portugués regula esta cuestión (mediante las denominadas áreas de continuidad) en su artículo quinto, en tanto que la ley marco española lo hace en el vigésimo. 


\section{II.2. Revisión y ampliación del concepto de área protegida}

Otra gran novedad en el plano programático tiene que ver con la revisión del concepto de área protegida. La extraordinaria expansión del territorio protegido en numerosos países, la asignación al mismo de nuevas funciones y cometidos, la delimitación de extensos parques que abarcan comarcas enteras -y en tierras de propiedad privada muy mayoritariamente-, son algunas de las razones explicativas de tal revisión. En efecto, en las últimas décadas los espacios protegidos han asumido progresivamente nuevos fines muy diversos y alejados de sus objetivos primigenios (conservación, investigación científica y recreación), de tal manera que hoy se espera de ellos que sean dinamizadores de la economía de los municipios implicados, que faciliten la inversión de fondos públicos específicos - a través de planes de desarrollo sostenible o similares-, que sean ámbitos de referencia para la educación ambiental, que doten de un distintivo de calidad a todo tipo de actividades o productos que se generen en su área de influencia, que contribuyan a la salvaguarda de los bienes del patrimonio cultural radicados en su interior, o que sean modelos de excelencia turística, entre otros muchos; todo ello en función del tipo de figura empleado de entre el prolijo catálogo creado a tal fin, al que nos referiremos posteriormente.

Pues bien, las estrategias protectoras hispano lusas han incorporado plenamente esta tendencia a la diversificación funcional de las áreas protegidas, que ya se anuncia desde las propias definiciones de las mismas donde se enfatizan su dimensión social o la preservación y valorización del paisaje y del patrimonio cultural. Así las define el ordenamiento jurídico portugués:

“(...) aquellas áreas terrestres y acuáticas interiores y áreas marinas en que la biodiversidad u otros elementos naturales presenten, por su rareza, valor científico, ecológico, social o escénico, una relevancia especial que exija medidas específicas de conservación y gestión, en orden a promover la gestión racional de los recursos naturales y la valorización del patrimonio natural y cultural, reglamentando las intervenciones artificiales que pudieran degradarlas" (DLCNB, art. 10.2).

Por su parte, la ley marco española se manifiesta de forma más genérica, pues han sido las comunidades autónomas las encargadas de impulsar la multifuncionalidad de los nuevos espacios protegidos, a partir de la siguiente definición básica:

"Tendrán la consideración de espacios naturales protegidos los espacios del territorio nacional, incluidas las aguas continentales, y el medio marino, junto con la zona económica exclusiva y la plataforma continental, que cumplan al menos uno de los requisitos siguientes y sean declarados como tales:

a) Contener sistemas o elementos naturales representativos, singulares, frágiles, amenazados o de especial interés ecológico, científico, paisajístico, geológico o educativo. 
b) Estar dedicados especialmente a la protección y el mantenimiento de la diversidad geológica, de la geodiversidad y de los recursos naturales y culturales asociados" (LPNB, art.27).

\section{II.3. Hacia una mayor implicación social en la gestión de las áreas protegidas}

La responsabilidad que implica la gestión de las actuales redes de áreas protegidas y la necesidad de desarrollarla desde perspectivas más integradoras, ha llevado a plantear nuevas fórmulas de participación de los municipios, del sector privado y de organizaciones y entidades de la sociedad civil en su conservación. Se trata de reforzar la presencia del tejido social de modo que se reduzcan el protagonismo de las administraciones y la intervención vertical imperantes durante décadas. Se busca en definitiva que las áreas protegidas sean mejor valoradas socialmente y lleguen a ser percibidas por las comunidades locales como un importante activo patrimonial.

En el caso de Portugal éste es un tema especialmente sensible debido al peso de un modelo tradicional de gestión que deja en manos de una sola entidad (ICNB y ahora ICNF) ${ }^{8}$ la responsabilidad de las áreas protegidas (Otero, 2009), quedando la participación social limitada a los periodos de discusión pública previos a la declaración de las áreas protegidas y a la elaboración de planes de ordenación. Por su parte, la composición de los denominados Consejos Estratégicos tampoco ha permitido la representación adecuada de los diferentes colectivos interesados ni la acción concertada de los mismos.

Con base en lo anterior, distintos especialistas portugueses vienen insistiendo en el predominio, entre las poblaciones rurales, de una arraigada postura defensiva frente a la protección de la naturaleza. Las restricciones que conlleva la constitución de un área protegida parecen estar en el origen de tal desencuentro, pero también parece existir el sentimiento bastante extendido de que las áreas protegidas son una imposición "desde arriba", con la intervención de organismos de la administración central que son vistos como "intrusos" (Figuereido, 2008a). En términos sociales, Portugal no ha experimentado aún la transformación necesaria y los nuevos presupuestos en materia de conservación de la naturaleza aún no han calado en la sociedad; en tal sentido Otero (2009) afirma que las plataformas dedicadas a las áreas protegidas, dirigidas a intercambiar experiencias, compartir información y ejercer presión sobre la política medioambiental prácticamente no existen. No obstante, muchas cosas parecen estar cambiando recientemente en lo referido a la consideración política, social y técnica de las áreas protegidas, y así lo reconocen también las autoras citadas. En definitiva se va asumiendo la idea de que la mejor estrategia para la conservación de la naturaleza y la biodiversidad es invertir en empoderamiento local (Queirós, 2012), aunque tal reconocimiento aún no ha tenido traslado desde el plano científico hasta el ámbito jurídico. Es reseñable también, como intento de descentralización de la gestión, la instauración de la figura de Área Protegida de Estatuto Privado, aunque sin mucho éxito en su aplicación hasta la fecha.

Desde la coincidencia en los planteamientos tendentes a una mayor implicación social, el avance español en la materia ha sido sustancial en las últimas décadas, aunque falta mucho

8 Instituto da Conservaçâo da Natureza e Biodiversidade (ICNB). Instituto da Conservaçâo da Natureza y das Florestas (ICNF) 
para dotar a colectivos locales y propietarios particulares del protagonismo que les corresponde. Al respecto, la intervención autonómica desde los años ochenta ha conllevado un reforzamiento de los órganos básicos de participación social (Patronatos y Juntas Rectoras), cuya función está siendo crucial en la gestión de Parques y Reservas, y también en la elaboración de los principales instrumentos de planificación (Planes de Ordenación de Recursos Naturales; Planes Rectores de Uso y Gestión; Planes de Desarrollo Sostenible, etc.) en varias comunidades autónomas. Por último, no se olvide que la LPNB regula la promoción de la custodia del territorio ( art. $72^{\circ}$ ), y los incentivos a las externalidades positivas en el ámbito de los espacios protegidos y de los acuerdos de custodia del territorio (art. $73^{\circ}$ ), con la misma intención de lograr una gestión más participativa.

\section{LA CONFLUENCIA DE DOS MODELOS DE PROTECCIÓN EN LA PENÍNSULA IBÉRICA: CLA- VES EXPLICATIVAS}

Como ya indicamos en el apartado introductorio, lo verdaderamente relevante en este análisis comparado de los sistemas protectores ibéricos es que la renovación programática llevada a cabo por España y Portugal -sincrónica y coincidente en sus postulados teóricos, como acabamos de comprobar-, se está desarrollando en la práctica mediante estrategias, instrumentos y figuras diferentes de un lado a otro de la frontera, dando paso a una situación paradójica, desde el momento en que colisiona con planteamientos esenciales del paradigma protector imperante, tales como la necesidad de lograr una mayor armonización interterritorial en materia de clasificación, planificación y gestión de las áreas protegidas. A continuación presentaremos los principales elementos de disparidad en orden a ilustrar la situación actual y los interrogantes que la misma plantea en el contexto de la preservación de la biodiversidad, la ordenación territorial y el desarrollo socioeconómico de extensísimas áreas rurales afectadas en ambos países.

\section{III.1. El diseño territorial de la protección}

Aquí se encuentra, sin duda, el primer y más importante elemento diferenciador entre las estrategias de protección implementadas por los Estados ibéricos. El sistema protector luso se apoya en una estructura integradora, jerárquica y centralizada, que se concreta en la denominada Red Fundamental de Conservación de la Naturaleza (RFCN), compuesta a su vez por dos grandes conjuntos de elementos patrimoniales:

a) El Sistema Nacional de Áreas Clasificadas (SNAC), formado por las denominadas áreas nucleares, es decir: Áreas Protegidas integradas en la Red Nacional de Áreas Protegidas (RNAP), Sitios de la Red Natura 2000, y demás áreas clasificadas al abrigo de compromisos internacionales (Reservas de la Biosfera, Humedales Ramsar, etc.).

b) Las áreas de continuidad, mediante las que se pretende asegurar la conexión territorial y el intercambio genético de poblaciones entre los diferentes ámbitos del apartado anterior. Tienen esta consideración las siguientes figuras del ordenamiento portugués: 
la Reserva Ecológica Nacional (REN)9 ${ }^{9}$, la Reserva Agrícola Nacional (RAN) y el Dominio Público Hídrico (DPH). A su vez, las áreas protegidas convencionales que integran la RNAP -objeto esencial de este trabajo- pueden obedecer a la siguiente tipología: Parque Nacional, Parque Natural, Reserva Natural, Paisaje Protegido, Monumento Natural y Área Protegida de Estatuto Privado.

Por el contrario, el modelo territorial español -configurado desde la pasada década de los ochenta ${ }^{10}$ - se asienta sobre una estructura de redes regionales yuxtapuestas, dando lugar a una arquitectura protectora heterogénea y extraordinariamente compleja. Como se ha explicado en páginas anteriores, la ley vigente vino a sistematizar y definir las tres grandes realidades territoriales en la materia: los Espacios Naturales Protegidos, los Espacios Protegidos Red Natura 2000, y las Áreas Protegidas por Instrumentos Internacionales. Sin embargo, a partir de ahí, la capacidad competencial de las comunidades autónomas en conservación de la naturaleza y ordenación territorial ha dado paso a un modelo poliédrico y muy cambiante, donde cada autonomía, en virtud de sus propios iniciativas legislativas, establece figuras propias de protección (existen alrededor de cuarenta distintas en la actualidad), selecciona y declara espacios protegidos desde una perspectiva estrictamente regional (en conjunto más de 1.600 hasta la fecha) y, finalmente, les otorga el papel que han de desempeñar en la ordenación territorial de la región, desde criterios en muchos casos dispares, incluso entre autonomías limítrofes.

\section{III.2. Dinámica protectora y figuras de protección}

El análisis evolutivo de las redes protectoras de España y Portugal desde 1980 pone de manifiesto el importante crecimiento reciente que atestiguan las cifras recogidas en la tabla 1. Aunque los datos están referidos sólo al territorio peninsular y a la red convencional de espacios protegidos -es decir, sin considerar la Red Natura ni los restantes instrumentos internacionales-, es evidente la intensidad del proceso expansivo tanto en número de declaraciones como en superficie protegida. Es cierto, no obstante, que con ritmos muy diferentes: España pasa de 184.270 a casi 6,6 millones de hectáreas, mientras Portugal lo hace de 329.168 a 792.220 hectáreas, e igualmente clara es la diferencia a favor de España en número de declaraciones pues sus 1662 espacios naturales contrastan con los 46 que registra el país vecino.

Entre las causas explicativas de tal disparidad sobresale, sin duda, la diferente organización político-territorial de cada estado y su régimen competencial. Es evidente que la expansión protectora hispana ha de vincularse directamente a la Constitución de 1978 y a la descentralización de competencias surgida de la misma, que otorgó a las regiones la capa-

9 Es preciso aclarar que la REN es una figura estratégica de ordenación territorial creada en 1983 (D.L. $321 / 83$, de 5 de julio, revisado en 1990, 2006 y 2008) con la finalidad de proteger los recursos naturales y favorecer la conservación de la biodiversidad. No obstante en los últimos años ha quedado relegada a un segundo plano (Freitas, 2012)

10 Téngase presente no obstante que la declaración de las primeras áreas protegidas españolas se remonta a principios de la pasada centuria, con lo que las bases remotas del actual sistema protector anteceden a las primeras iniciativas lusas en más de medio siglo (Mulero, 1995 y 2002). 
cidad para legislar, seleccionar y declarar espacios protegidos en sus respectivos territorios. Por el contrario, la permanencia de una estructura muy centralizada en el caso de Portugal se presenta como el factor fundamental -aunque no el único- a la hora de explicar su modesto catálogo actual; una impresión que se confirma al analizar la diferente evolución de las regiones autónomas portuguesas, que sí disponen de competencias propias en la materia: Azores registra 133 áreas protegidas y Madeira otras 26, superando ampliamente el elenco del territorio peninsular.

El contraste anterior se manifiesta igualmente en las figuras o categorías protectoras empleadas (Tablas 2 y 3): frente al criterio luso de la simplificación, se sitúa la apuesta hispana por una diversificación que ha llegado a ser abrumadora. De entrada, ambos países han establecido en su legislación básica sólo seis figuras de referencia, coincidentes a grandes rasgos en su formulación. Las principales diferencias son: el desdoblamiento de las categorías portuguesas que -con la excepción del Parque Nacional-pueden tener un carácter estatal o regional/local; la presencia del Área Marina Protegida incluida en el ordenamiento español, y el reconocimiento del Área de Gestión Privada en el portugués. Sin embargo, frente a esta contención inicial, muy en la línea de las recomendaciones de la UICN, la intervención de las autonomías hispanas ha generado otras cuarenta figuras de protección aproximadamente (Mulero, 2002; EUROPARC, 2014), muchas de las cuales (Parque Regional, Parque Rural, Microrreserva, Reserva Natural Parcial y otras) no son sino variantes propias de las citadas figuras básicas. Pero no se trata sólo de un problema de excesiva diversificación. La desmedida proliferación de figuras está provocando serias distorsiones, tanto por la existencia de varias que, con idéntica denominación, persiguen fines diferentes -según la autonomía en que se encuentren-, como por la situación inversa. En definitiva, la adopción de una perspectiva estrictamente regional ha venido a restar coherencia territorial a la expansión protectora hispana, a la vez que dificulta su percepción y comprensión social: hoy sólo una ínfima parte de la población española es capaz de diferenciar entre las figuras de protección y los objetivos que persiguen.

Por su parte la actual duplicación de las figuras básicas, propia del sistema peninsular portugués, ha de ser interpretada también en términos político-administrativos, como un reconocimiento al peso de las municipalidades en la gestión del territorio luso (adviértase que en realidad la denominación de área protegida de ámbito regional se aplica simplemente cuando en la propuesta de declaración se unen dos o más municipios, sin que ello implique rango o competencias superiores a las del área protegida de ámbito local).

Mientras las áreas de rango nacional han de ser propuestas por la autoridad nacional o por cualquier entidad pública o privada (especialmente municipios o asociaciones de defensa del medio ambiente), el resto ha de surgir a iniciativa de un municipio (rango local) o de una asociación de dos o más de ellos (rango regional), con la condición previa de que sus respectivos Planes Municipales de Ordenación del Territorio reconozcan el área y prevean un régimen de protección adecuado para la misma. Finalmente, la propuesta de constitución de Áreas Protegidas de Estatuto Privado ha de partir del propietario de los terrenos y someterse a la posterior aceptación de la administración medioambiental, previa aprobación de un protocolo para su gestión. No obstante, aunque estas áreas forman parte de la RNPA, su declaración no condiciona en modo alguno lo dispuesto en los planes de gestión territorial vigentes. 
Otra importante diferencia, ilustrativa de la visión más compacta e integradora del modelo portugués, es la posibilidad de delimitar reservas integrales y microrreservas en el interior de cualquier área protegida. Las primeras se crean con la finalidad de mantener los procesos naturales sin injerencia de actividades humanas, y las segundas se orientan a la conservación de pequeñas áreas aisladas ocupadas por una o varias especies y/o hábitats amenazados. En el territorio español, en cambio, las mismas existen como figuras específicas de protección en algunas comunidades autónomas (Tabla 4).

Por último, en relación con el uso y el significado de las figuras protectoras es preciso señalar que, pese a las diferencias destacadas, en ambos países las redes se articulan esencialmente en torno a la figura de Parque Natural (58\% de la superficie protegida en España y $79 \%$ en Portugal), que ha adquirido un peso territorial considerable (Queirós, 2001; Mulero, 2002). Sin duda, sus objetivos amplios y flexibles han posibilitado que se adapte muy bien a la nueva concepción más abierta de área protegida, comentada en el anterior epígrafe. No obstante, resulta paradójico que se trate de una figura ajena a las establecidas por la Unión Internacional para la Conservación de la Naturaleza (UICN), lo que obliga a homologarla con otras categorías UICN, como Área Protegida con uso sostenible de los recursos naturales o Paisaje Protegido, figura ésta última que, por el contrario, ha tenido muy escaso reconocimiento en España (Mulero, 2013).

Tabla 2

RED NACIONAL DE ÁREAS PROTEGIDAS (RNAP) DE PORTUGAL CONTINENTAL (2015)

\begin{tabular}{|l|l|c|c|}
\hline Tipología & Ámbito/gestión & Número & Extensión (ha) \\
\hline Parque Nacional & Estatal & 1 & 69.592 \\
\hline Parque Natural & Estatal & 13 & $596.519,59$ \\
\hline Reserva Natural & Estatal & 9 & $74.080,09$ \\
\hline Paisaje Protegido & Estatal & 2 & $1.924,9$ \\
\hline Monumento Natural & Estatal & 7 & 1.157 \\
\hline & Total ámbito estatal & $\mathbf{3 2}$ & $\mathbf{7 4 3 . 2 7 3 , 5 8}$ \\
\hline Parque Natural Regional & Regional/Local & 1 & 24.767 \\
\hline Reserva Natural Local & Regional/Local & 2 & 120,13 \\
\hline Paisaje Protegido Regional & Regional/Local & 6 & $21.632,48$ \\
\hline Paisaje Protegido Local & Regional/Local & 4 & $2.212,41$ \\
\hline & Total ámbito regional/local & $\mathbf{1 3}$ & $\mathbf{4 8 . 7 3 2 , 0 2}$ \\
\hline Área protegida privada & Privado & 1 & 214,67 \\
\hline & Total ámbito privado & $\mathbf{1}$ & $\mathbf{2 1 4 , 6 7}$ \\
\hline & TOTAL GENERAL & $\mathbf{4 6}$ & $\mathbf{7 9 2 . 2 2 0 , 2 7}$ \\
\hline
\end{tabular}

Fuente: Instituto da Conservaçao da Natureza e das Florestas (Portugal) e Planos de Ordenamento das Áreas Protegidas. Elaboración Propia. 
Tabla 3

RED DE ESPACIOS NATURALES PROTEGIDOS DE ESPAÑA PENINSULAR (2013)

\begin{tabular}{|l|l|c|c|}
\hline Tipología & Ámbito/gestión & Número & Extensión (ha) \\
\hline Parque Nacional & Estado-C. Autónomas & 10 & 321.832 \\
\hline Parque Natural & C. Autónomas & 132 & 3.769 .341 \\
\hline Reserva Natural & C. Autónomas & 269 & 168.564 \\
\hline Monumento Natural & C. Autónomas & 274 & 57.173 \\
\hline Paisaje Protegido & C. Autónomas & 26 & 102.427 \\
\hline Área Marina Protegida & C. Autónomas & 1 & 234.950 \\
\hline $\begin{array}{l}\text { Otras treinta y siete figuras de } \\
\text { creación autonómica }\end{array}$ & C. Autónomas & 950 & 1.923 .425 \\
\hline Total & & $\mathbf{1 . 6 6 2}$ & $\mathbf{6 . 5 7 7 . 7 1 2}$ \\
\hline
\end{tabular}

Fuente: Elaboración propia a partir de datos procedentes de: Europarc España; Ministerio de Agricultura y Medio Ambiente (España).

\section{III.3. Competencias y estrategias de gestión: el modelo centralizado versus la disparidad regional}

En el ámbito de la gestión encontramos otro claro exponente de la actual coexistencia de dos formas diferentes de entender la protección en la Península Ibérica. Como se ha explicado arriba, las áreas protegidas que integran la red portuguesa -con la excepción del Parque Nacional- pueden tener un rango nacional o regional/local, y también existen las de régimen privado, aunque en la práctica son las áreas protegidas de ámbito nacional y gestión centralizada las absolutamente dominantes en el conjunto de la RNPA del Portugal continental (Tabla 2). Un modelo de gestión centraliza que afecta incluso a las áreas protegidas de rango local o regional, ya que la autoridad nacional mantiene funciones de supervisión y evaluación de las que depende su existencia. Ni que decir tiene que tal modelo tiene consecuencias notables, entre las que a nuestro juicio sobresalen las que siguen:

$1^{\mathrm{a}}$. La contenida expansión territorial de la red portuguesa en su conjunto puede relacionarse con la intervención excesivamente vertical que se ha venido realizando desde Lisboa hacia las autarquías, protagonizada por organismos estatales muy centralizados (antes ICNB y ahora ICNF), que no han logrado en muchos casos la implicación del tejido local ni su confianza en las bondades y beneficios de las políticas de conservación. Y esto, a su vez, ha aumentado el rechazo frente a las restricciones que pueda implicar la declaración de nuevas áreas protegidas; los relatorios ${ }^{11}$ que acompañan a los Planes de Ordenación de las Áreas Protegidas (POAP), son muy ilustrativos de la oposición local al respecto y permiten entender tanto el retraso en la aprobación de

11 Nos referimos a los Relatórios de Ponderaçâo da Discussâo Pública elaborados durante el procedimiento de aprobación de cada uno de los Planos de Ordenamento de las respectivas áreas protegidas portuguesas 
los planes, como la escasez de iniciativas locales para la declaración de nuevas áreas (sólo existen trece en todo el país, con unas 49.000 ha)

$2^{\text {a }}$. En estrecha relación con lo anterior, es muy probable que los respectivos Planes Municipales de Ordenación Territorial -de los que depende el reconocimiento y la viabilidad de cualquier área protegida local o regional- se vengan elaborando desde una postura anticonservacionista y defensiva frente a la tradicional intervención vertical desde Lisboa y las consiguientes limitaciones o cortapisas que pudieran traer nuevas declaraciones; no se olvide además que la autoridad nacional mantiene la capacidad de evaluación y supervisión de las áreas protegidas de ámbito local y regional, lo cual puede ser una razón fundamental de la escasez de propuestas para nuevas clasificaciones.

$3^{\text {a }}$. El modelo centralizado imperante no parece haber favorecido tampoco el desarrollo de las denominadas Áreas Protegidas Privadas (sólo una declaración con 215 ha); de una parte son escasos los incentivos que el modelo portugués ofrece frente a las responsabilidades que el promotor particular contrae, y también concurre una acusada falta de tradición en lo relacionado con el patrocinio y la implicación del sector privado en la protección medioambiental.

Al otro lado de la frontera el panorama, sin embargo, es completamente opuesto, porque en el modelo hispano la gestión de los espacios naturales descansa absolutamente en los entes regionales. Una excepción parcial a tal disposición se encuentra en los Parques Nacionales, que conforman una red diferenciada y regulada por una ley específica ${ }^{12}$; sólo en relación con esta figura el Estado mantiene funciones de coordinación y seguimiento, y en algún caso ha asumido la gestión compartida de algunas piezas (Parques Nacionales de Tablas de Daimiel y Cabañeros, en la Comunidad de Castilla-La Mancha) ${ }^{13}$.La consecuencia fundamental de este modelo regional es la yuxtaposición de quince estructuras de gestión de áreas protegidas en el territorio peninsular español bastante heterogéneas entre sí.

Por otra parte, a diferencia de Portugal, en España los municipios carecen de capacidad para gestionar directamente áreas protegidas -con algunas excepciones muy puntuales-, aunque sí participan de forma indirecta a través de su representación en Patronatos y Juntas Rectoras. Y tampoco la legislación marco española contempla una figura similar al área protegida bajo estatuto privado existente en el país vecino, si bien es cierto que algunas autonomías han creado categorías parecidas, en la línea de las Reservas Naturales Concertadas de Andalucía.

\section{III.4. Planificación de áreas protegidas y ordenación del territorio: dos concepciones dispares}

En lo concerniente a la planificación de las áreas protegidas, Portugal ha establecido un modelo muy interesante en el plano teórico al apostar por dos atributos tan poco comunes en

12 Ley 30/2014, de 3 de diciembre, de Parques Nacionales.

13 En realidad, la intervención estatal ha quedado reducida a la promulgación de la normativa básica -en cualquier caso muy consensuada con los órganos regionales- y a labores de armonización y coordinación de redes específicas, como la citada de Parques Nacionales o la "futura" Red de Áreas Marinas Protegidas definida por la LPNB (2007). 
la actualidad como la tendencia a la simplificación de instrumentos y la armonización entre planificación ambiental y planificación territorial. En efecto, la legislación portuguesa contempla un único instrumento específico, el Plan de Ordenación del Área Protegida (en adelante POAP), con vigencia indefinida y obligatorio sólo para las figuras de Parque Nacional y Parque Natural de ámbito estatal, aunque las Reservas Naturales y los Paisajes Protegidos estatales podrán disponer de uno si sus respectivos decretos declarativos indican su necesidad. En la actualidad, ya son 25 las áreas protegidas de rango estatal que disponen de un Plan de Ordenación (1 Parque Nacional, 13 Parques Naturales, 9 Reservas Naturales y 2 Paisajes Protegidos). Sin duda, esta simplificación operativa contrasta con la situación española como se explicitará después.

No obstante, pronto se hacen evidentes algunas debilidades importantes en el modelo portugués. De entrada, los decretos declarativos de las respectivas áreas protegidas estipulan -de forma genérica- que tanto los planes municipales e intermunicipales de ordenación territorial como los programas y proyectos a realizar en el área protegida deberán adaptarse a los POAP, pero nótese que esta prevalencia de la planificación ambiental sobre la planificación territorial pierde mucha solvencia por el extraordinario retraso acumulado hasta la aprobación del documento final. Como acertadamente nos recuerda Pinto $(2008)^{14}$, el tiempo medio entre la declaración de un área protegida y la aprobación de su primer plan de ordenación ha sido de aproximadamente veinte años.

Otro punto débil del modelo luso está relacionado con la planificación de las áreas protegidas de ámbito local o regional. El legislador no ha considerado necesario que las mismas dispongan de un plan de ordenación específico, de modo que han de regirse por lo dispuesto en los respectivos Planes Municipales de Ordenación Territorial. Así, lo que en principio puede parecer una disposición interesante y lógica, que busca incardinar la planificación ambiental en el seno de la planificación territorial, se ve comprometida por:

$1^{\circ}$ La dificultad para alcanzar una coordinación estrecha y eficaz cuando son varios los municipios implicados: de entrada a la hora de acometer una redacción consensuada de sus respectivos planes de ordenación territorial, de los que dependerá la viabilidad y el funcionamiento de las áreas protegidas intermunicipales o regionales.

$2^{\circ}$ El conflicto de intereses en el seno de los municipios que pretendan impulsar la declaración de cualquier área protegida, ya sea ésta de ámbito local o regional (Pereira da Silva, 2000). No se olvide que al estar incardinada la planificación ambiental en la planificación territorial del municipio, es evidente el riesgo de prevalencia de los intereses locales - de naturaliza urbanística o económica- sobre las necesidades ambientales o de conservación. Como ya se ha indicado, las alegaciones recogidas en los relatorios de diversas áreas protegidas manifiestan con carácter general el desencuentro entre áreas protegidas y tejido social.

14 "All mainland PA with national importance have approved management plans, which is mainly due to the large effort in the last years to conclude them (...). However, it should be said that the medium time between the creation of these areas and the approval of their first management plan was approximately 20 years" (PINTO, 2008, 104). 
Por su parte, el modelo español se aleja sustancialmente del esquema aplicado en Portugal. En primer lugar, la arquitectura planificadora hispana se apoya en dos instrumentos esenciales: el Plan de Ordenación de los Recursos Naturales (en adelante PORN) y el Plan Rector de Uso y Gestión (en adelante PRUG). En la actualidad, 10 de los 15 Parques Nacionales cuentan con un PORN, así como 126 de los 149 Parques Naturales; en tanto que disponen de PRUG 11 Parques Nacionales y 78 Parques Naturales. No obstante algunas comunidades autónomas han creado otros instrumentos complementarios con rango normativo (Normas de Gestión, Normas de Protección, Plan de Protección, entre otros) e incluso algunas herramientas que, sin alcanzar tal rango, tienen mucha importancia en la gestión cotidiana, caso de los programas anuales de gestión en Cataluña (Europarc, 2013).

De cualquier forma, el PORN es el auténtico referente del sistema planificador español, por tres razones esenciales: porque es obligatorio para Parques y Reservas, porque ha sido dotado de una fortaleza jurídica sin precedentes en la legislación hispana en la materia, y porque ha superado el concepto tradicional de plan elaborado a posteriori, una vez declarada el área protegida. Ahora éste tiene la condición de instrumento general de ordenación del patrimonio natural y de los recursos naturales de un determinado territorio, pudiendo llegar a abarcar la totalidad de una comunidad autónoma (sería el caso del PORN del Principado de Asturias $)^{15}$; por ello el plan de ordenación es el encargado de señalar los ámbitos necesitados de un régimen de protección específica y el tipo de figura a aplicar (LPNB, art. 18.1), y no al contrario, como ha venido siendo práctica habitual. Y aún más importante es el hecho de que las disposiciones contenidas en este plan prevalezcan sobre las de cualquier otro instrumento de ordenación territorial, urbanística, de recursos naturales y, en general, física, en caso de conflicto o cuando sean contradictorias entre sí (art. 19.2).

El otro gran elemento diferenciador con relación al modelo luso es que la responsabilidad del desarrollo y ejecución de los instrumentos de planificación recae en la escala regional, es decir, en las comunidades autónomas, que son las responsables de establecer, en sus respectivos ámbitos, el modelo de relación entre la planificación ambiental y la planificación territorial.

Por último, a efectos jurídicos, la prevalencia otorgada al PORN sitúa la planificación ambiental -en lo concerniente al patrimonio natural y a la ordenación los recursos naturales- muy por encima de la planificación territorial, en lugar de estar integrada en ésta o supeditada a ella. Así se entiende que en numerosas ocasiones ambas prácticas planificadoras discurran por caminos separados, un buen ejemplo de lo cual lo tenemos en Andalucía -la primera región por superficie protegida- donde tanto su plan marco de ordenación del territorio (POTA, 2006), como los posteriores planes subregionales regionales aprobados han debido adaptar sus disposiciones a una red de áreas protegidas de 1.6 millones de hectáreas -creada previamente por el organismo medioambiental-y al complejo sistema planificador que la misma incorpora.

15 Los Planes de Ordenación de los Recursos Naturales son el instrumento específico para la delimitación, tipificación, integración en red y determinación de su relación con el resto del territorio, de los sistemas que integran el patrimonio y los recursos naturales de un determinado ámbito espacial, con independencia de otros instrumentos que pueda establecer la legislación autonómica. Su vigencia y plazos de revisión serán definidos por la normativa de las comunidades autónomas o, en el ámbito de sus competencias, por la Administración General del Estado (LPNB, art. 17.1). 


\section{III.5. La desigual importancia otorgada a las áreas protegidas como vehículo de desarrollo económico y social}

Desde la formulación de las Reservas de la Biosfera, por parte de la UNESCO, se ha venido consolidando una corriente de opinión favorable a que las áreas protegidas tengan una mayor implicación en la dinamización social y económica de los municipios sobre los que se asientan. De este modo se compensarían parcialmente las limitaciones y prohibiciones que la protección conlleva y, además, se lograría una mayor implicación social en las políticas de conservación.

No obstante, tales planteamientos no parecen haberse asentado aún con fuerza suficiente en Portugal, donde la declaración de la mayor parte de las áreas protegidas ha obedecido a objetivos eminentemente naturalistas y conservacionistas sin una clara apuesta por la dimensión socioeconómica antedicha. Parece olvidarse que se trata de un reto fundamental para asegurar el respaldo social y, con ello, el buen funcionamiento de las áreas protegidas, la mayor parte de las cuales coincide con espacios rurales desfavorecidos y necesitados de nuevas estrategias de desarrollo. Figuereido (2008, 54), que ha estudiado con detalle la situación en diversos parques lusos, es taxativa al respecto cuando afirma que la intervención portuguesa en la materia "representa para los habitantes (...) una vulnerabilidad y una subordinación del bien común a intereses y necesidades externos". Por ello, desde hace años, se viene recomendando la implementación de iniciativas que ganen apoyo público y credibilidad para la política de áreas protegidas, en la línea de compensar las restricciones impuestas por la protección (Pinto, 2008; Pereira da Silva, 2000). Lamentablemente, en este aspecto el DLCNB (2008) no ha traído avances de consideración, al no contemplar plan ni instrumento alguno de desarrollo dirigido a los municipios implicados.

Pero ¿está resultando mejor, en el resto de la península, el proceso de integración socioeconómica de las áreas protegidas en sus zonas de influencia? Es difícil dar una respuesta absoluta porque, en realidad, la situación española es muy heterogénea a escala regional. En España aunque la legislación estatal tampoco reconoce instrumentos específicos orientados a este tipo de dinamización socioeconómica, sí lo hacen algunas normas autonómicas, de modo que al menos treinta y cinco parques españoles cuentan con un Plan de Desarrollo o herramienta similar (EUROPARC, 2014). Andalucía es la comunidad destacada al respecto, puesto que la totalidad de sus parques naturales dispone de un Plan de Desarrollo Sostenible $(\mathrm{PDS})^{16}$, que tienen como beneficiarios al conjunto de municipios que forman la denominada área de influencia socioeconómica. Tales planes persiguen, con carácter general, la mejora del nivel de vida de las poblaciones locales, razón por la cual en su elaboración se introdujeron interesantes mecanismos de participación social. Su principal aportación se concreta en un prolijo elenco de actuaciones a acometer que sobrepasan ampliamente las competencias de la administración ambiental e implican a otros muchos departamentos con competencias sobre el territorio (Mulero y Garzón, 2005).

16 Ley $2 / 1989$, de 18 de julio, por la que se aprueba el Inventario de espacios naturales protegidos de Andalucía y se establecen medias adicionales para su protección. Inicialmente eran denominados Planes de Desarrollo Integral. 


\section{III.6. Las nuevas fórmulas de coparticipación en el manejo y financiación de las áreas protegidas}

Desde otra perspectiva, la aspiración a una mayor implicación social en el funcionamiento de las áreas protegidas se manifiesta también en el debate abierto sobre la pertinencia de incorporar nuevas fórmulas que permitan una coparticipación público-privada en su gestión. Como consecuencia del mismo, la legislación portuguesa ha incorporado diferentes medidas (DLCNB, art.35) para que las autarquías locales, el sector privado, las organizaciones representativas de la sociedad civil y otras entidades públicas, puedan participar en el manejo de los territorios que integran el Sistema Nacional de Áreas Clasificadas (SNAC). Una coparticipación público-privada inspirada en los planteamientos de la Directiva Hábitat que, desde un carácter marcadamente opcional, establece varios tipos de herramientas para intervenir en la gestión de las áreas protegidas, según Morais (2013) con claros ejemplos en el contrato de aparcería público-privada, el contrato de gestión, el contrato de concesión de uso o explotación de bienes inmóviles demaniales o privados del Estado y también en contratos de financiación bajo la fórmula de "instrumentos de compensación ambiental" para sostener los costes de las exigencias del régimen de evaluación del impacto ambiental o de la Red Natura 2000. Sin embargo, a juicio del citado autor tales herramientas son injustas en algunos casos, al generar costes al erario público del país que debieran ser compartidos con el sector privado, y señala como ejemplo la explotación de utilidades turísticas vinculadas a las áreas protegidas lusas.

En esta materia, aunque la última ley española también ha incorporado fórmulas para la colaboración público-privada, las herramientas elegidas han sido diferentes y más centradas en la estricta conservación del patrimonio natural y la biodiversidad. Por ejemplo, resulta clave la custodia del territorio, en virtud de la cual la Administración General del Estado podrá establecer acuerdos con las denominadas entidades de custodia para la cesión de la gestión de terrenos a su cargo emplazados en espacios naturales, siempre sin ánimo de lucro y a través de unos acuerdos de cesión que preverán el sistema de financiación para su desarrollo (LPNB, art. 76.2).

Un asunto distinto del anterior es el de la cofinanciación de las áreas protegidas, materia en la que los planteamientos luso e hispano también difieren en lo esencial. En Portugal la norma permite su instauración (DLCNB, Cap. V), con el fin de contribuir al coste de un patrimonio natural en expansión que demanda cada vez mayores medios e inversión pública; entre los diferentes tipos de medidas recaudatorias aplicables en las áreas protegidas están las tasas por el acceso a las mismas, o por la disponibilidad de bienes y servicios radicados en su interior, o también la concesión a terceros de la explotación comercial de las marcas asociadas al SNAC. Muy probablemente las medidas en esta línea son una manifestación del conservacionismo utilitarista imperante en la sociedad lusa con respecto a su sistema de parques (Queirós, 2012,590), a los que se percibe principalmente como una herramienta para la creación de empleo, el incremento de rentas, etc.

No obstante, y a pesar de los costes crecientes que implica la protección de tan extenso territorio, los planteamientos hispanos en la materia son contrarios a la aplicación de este tipo de tasas y, de hecho, cuando se promulgó la ley en vigor se volvió a apostar por una mayor financiación pública al incorporar ayudas a entidades sin ánimo de lucro (siempre que sean 
de ámbito estatal, estén presididas por un objetivo de conservación del patrimonio natural y la biodiversidad, y sus actuaciones afecten a más de una comunidad autónoma), incentivos a las externalidades positivas, con el fin de recompensar a los propietarios de terrenos incluidos en espacios protegidos que generen efectos positivos para la conservación, y, por último un fondo para el Patrimonio Natural y la Biodiversidad que se dotará con las partidas asignadas en los Presupuestos Generales del Estado.

\section{CONCLUSIONES}

La intensidad del reciente ciclo protector está deparando consecuencias territoriales, ecológicas y socioeconómicas de primera magnitud en la Península Ibérica. Al respecto, España y Portugal han canalizado la extraordinaria ampliación de sus redes de áreas protegidas mediante la renovación paralela de su normativa e instrumentos, y partiendo de unos objetivos programáticos bastante similares en términos teóricos. Así parece indicarlo la apuesta de ambos por una gestión holística del patrimonio natural territorial, por la ampliación de las funciones encomendadas a las áreas protegidas, o por conveniencia de fortalecer la participación social, de modo que se mejore la implicación de las poblaciones locales en las políticas protectoras.

Sin embargo, al descender al análisis de la praxis propia de cada país queda de manifiesto que, pese a las semejanzas aparentes, ambos están implementando en sus respectivos territorios fórmulas muy diferentes, e incluso opuestas en algunos aspectos, dando paso a la coexistencia de dos modelos protectores dispares sobre una geografía peninsular caracterizada ante todo por la continuidad y riqueza de su biodiversidad. El que sería considerado un proceder normal algunas décadas atrás, hoy colisiona con el paradigma imperante en la escena internacional, que apuesta por fortalecer la homogeneidad en los criterios de selección de áreas protegidas, garantizar la continuidad interterritorial de las redes protectoras (ya sean regionales, estatales o continentales), así como armonizar los objetivos, planificación y gestión de las mismas. Al respecto a lo largo de las páginas precedentes se han señalado numerosas cuestiones esenciales que sostienen la anterior afirmación. De entrada, en lo relacionado con el diseño territorial de las redes protectoras, se constata que mientras Portugal ha optado por una estructura integrada y jerarquizada, basada en la denominada Red Fundamental de Conservación de la Naturaleza, España se ha decantado por un modelo de redes regionales yuxtapuestas, que si bien aporta una mayor agilidad y proximidad en la declaración y gestión de las áreas protegidas, tiene en su contra la configuración de un entramado protector sumamente heterogéneo y complejo donde son frecuentes las contradicciones intra e interregionales.

El distanciamiento anterior se refuerza al analizar la tipología y aplicación de las figuras protectoras, con un panorama radicalmente distinto a cada lado de la frontera (seis figuras en Portugal por más de cuarenta en España). La contención en el número de declaraciones, el protagonismo absoluto de las figuras de rango estatal y el reconocimiento de las áreas protegidas de estatuto privado, son también rasgos diferenciadores del modelo luso. Por el contrario el boom protector español se ha apoyado en una intervención decidida de las diferentes comunidades autónomas, a las que se debe tanto la extraordinaria expansión protectora en términos territoriales, como la proliferación injustificada e innecesaria de figuras protectoras que, como se ha explicado, ha generado confusión y contradicciones diversas. 
Otro gran asunto controvertido se encuentra en el modelo de gestión: ¿puede abordarse el manejo de un territorio protegido cada vez más extenso desde una gestión centralizada en los organismos estatales, o es necesaria una descentralización basada en fórmulas regionales o locales?, y, por otra parte, ¿es conveniente la proliferación de áreas protegidas bajo gestión privada? Ambos son interrogantes básicos en la materia que España y Portugal valoran y encauzan de forma diferente, por lo que a nuestro juicio es necesario profundizar en el análisis de estos modelos de gestión en casos concretos, pues, como se ha explicado, los dos gozan de claros logros y carencias, que impiden formular un diagnóstico generalista o simplista.

En estrecha vinculación con lo anterior se sitúa el problema del sistema de planificación, que en Portugal pivota exclusivamente sobre los Planes de Ordenación de las áreas Protegidas (POAP), desde una apuesta por la simplificación y por su integración con los planes específicos de ordenación territorial; una concepción que, de entrada, podría ser valorada muy positivamente. Sin embargo, en la práctica, tal valoración queda rebajada al constatarse algunos escollos importantes, como la tardanza en la aprobación de estos planes (veinte años de media), o las dudas que suscita el papel protagonista de las municipalidades en la planificación de las áreas protegidas de rango local/regional. Por el contrario, en el modelo español, donde el peso fundamental recae en el Plan de Ordenación de los Recursos Naturales (PORN) -aunque en sintonía con otros instrumentos diversos (PRUG, PDS ,...)-, el problema no se encuentra tanto en la eficacia de estos instrumentos planificadores cuanto en los desajustes existentes entre planificación ambiental y planificación territorial, que con frecuencia están discurriendo por caminos separados.

Y muy importante es también la distancia hispano-lusa en lo relativo al modo de entender la dimensión socioeconómica de las áreas protegidas. En Portugal, paradójicamente -y pese a los favorables pronunciamientos científicos y técnicos a favor de que parques, paisajes protegidos y demás figuras asuman un mayor protagonismo en la dinamización de las economías locales- no se reconoce jurídicamente esta cuestión ni se la apoya con herramientas específicas. Así, en un proceder diferente al seguido en buena parte del territorio español, no se han regulado incentivos concretos o planes de desarrollo tendentes a este fin, por lo demás completamente necesarios si se considera que la mayoría de las áreas protegidas lusas coincide con ámbitos rurales desfavorecidos. Unos ámbitos que necesitan este tipo de revulsivos socioeconómicos y que, cada vez más, los demandan con insistencia como contrapartida a las limitaciones que imponen las políticas protectoras; y no se olvide que los objetivos de la protección son inalcanzables sin la connivencia de las comunidades locales.

También en el contexto socioeconómico, otro asunto en el que ambos Estados difieren sustancialmente es el relativo a las fórmulas de coparticipación público-privada en la gestión y en la financiación de los espacios protegidos. No obstante se trata de iniciativas recientes surgidas como respuesta a la extraordinaria expansión protectora y al crecimiento del gasto público derivado de la misma y, por lo tanto, es preciso esperar algún tiempo antes de emitir una valoración fundamentada acerca de la oportunidad de las mismas.

Sin duda las anteriores observaciones apuntan en conjunto a la necesidad de emprender nuevos trabajos centrados en áreas protegidas concretas -con especial atención a las de carácter transfronterizos- que comparten ambos estados que permitan aquilatar mejor las fortalezas y debilidades de estos dos modelos dispares de intervención protectora en el territorio ibérico. 


\section{BIBLIOGRAFÍA}

ARAUJO, M.B., LOBO, J.M. y MORENO, J.C. (2007): “The effectiveness of Iberian Protected Areas in Conserving Terrestrial Biodiversity". Conservation Biology, vol. 21, Issue $6,1423-1432$.

CASADO DE OTAOLA, S. (1997): Los primeros pasos de la ecología en España. Madrid, MAPA (Serie Estudios $\left.n^{\circ} 128\right)$.

DELGADO VIÑAS, C. (2008): “<Urbanización sin fronteras>. El acoso urbanístico a los espacios naturales protegidos”. Boletín de la Asociación de Geógrafos Españoles, $\mathrm{n}^{\circ}$ 47, 271-310.

EUROPARC (2014) Anuario 2013 del estado de las áreas protegidas en España. Madrid, Fundación Fernando González Bernáldez.

FIGUEIREDO, E. (2008a): “CCómo proteger a las personas en las áreas protegidas? El medio ambiente como vulnerabilidad en dos áreas protegidas portuguesas." Revista Española de Estudios Agrosociales y Pesqueros, $\mathrm{n}^{\circ}$ 220, 45-69.

FIGUEIREDO, E. (2008b): "Imagine there's no Rural -the transformation of rural spaces into places of nature conservation in Portugal" European Urban and Regional Studies, $15(2), 159-171$.

JOLLIVET, M (2007): “Les Métamorphoses d'un Rural Incertain”. In Jollivet, M (ed): Vers un Rural Postindustriel-Rural et Environnement en Huit Pays Européens, pp. 351-371. París. L'Harmattan.

LANDOVSKY y MENDES (2012) “As Áreas Protegidas em Portugal”. En: http://pluris2010.civil.uminho.pt/Actas/PDF/Paper397.pdf

MORAIS GUERRA, J.A. (2013) Espacios naturales protegidos en el ordenamiento jurídico portugués. Madrid, Ed. Colex.

MULERO MENDIGORRI, A. (2002) La protección de espacios naturales en España. Madrid, Mundi-Prensa.

MULERO MENDIGORRI, A. (2013): “Significado y tratamiento del paisaje en las políticas de protección de espacios naturales en España" Boletín de la Asociación de Geógrafos Españoles, $\mathrm{n}^{\circ}$ 62, 129-145.

MULERO MENDIGORRI, A. (2015): "Hacia la gestión integrada del patrimonio territorial: un análisis crítico desde la experiencia andaluza”. Investigaciones Geográficas, 63, 69-84.

MULERO, A. y GARZÓN, R (2005): “ Espacios naturales protegidos y desarrollo rural en España: Los Planes de Desarrollo Sostenible”. Ería, n 68, 315-330.

OJEDA RIVERA, J.F. (1999): “Espacios naturales protegidos y desarrollo sostenible”. En Valle, B. (Coord.): Geografía y espacios protegidos. Murcia, Asociación de Geógrafos Españoles, 273-286.

OTERO, J. (2009): Análise comparativa de modelos de gestâo de Áreas Protegidas em países da Uniâo Europeia. Lisboa, Tese de Mestrado. Faculdade de Ciencias. Universidade de Lisboa.

PEREIRA DA SILVA, C. (2000) “Areas protegidas em Portugal: Que papel? Conservaçao versus desenvolvimento". GeoINova, n 2, 27-44. 
PINTO, B-L.M. (2008): Historical information of the Portuguese Protected Areas and its implications for management. Dissertaçâo apresentada para obtençâo do Grau de Doutor. Lisboa, Universidade Nova de Lisboa.

QUEIRÓS, M. (2001/2): “Os parques naturais e o ordenamento do território em Portugal”. Inforgeo, 16-17, 141-150

QUEIRÓS, M. (2012): "Natural Parks in Portugal: a way to become more ecologically responsible?" Environment and History, vol, 18 (4), 585-611.

TROITIÑO VINUESA, M.A. et al. (2005): "Los espacios protegidos en España: Significado e incidencia territorial". Boletín de la Asociación de Geógrafos Españoles, n ${ }^{\circ} 39,227-$ 265. 
